\title{
Questionamento em manuais escolares: um estudo no âmbito das Ciências Naturais
}

\author{
Questioning in textbooks: a study in the scope \\ of Natural Sciences
}

Joana Torres $^{1}$ • António Almeida ${ }^{2}$ - Clara Vasconcelos ${ }^{3}$

\begin{abstract}
Resumo: A Aprendizagem Baseada na Resolução de Problemas é uma metodologia de ensino, fundamentada no Ensino por Investigação, que pretende promover o desenvolvimento de diversas competências, que possibilitem o estímulo do raciocínio científico, a autonomia e o desenvolvimento de capacidades de questionamento e reflexão críticas. Neste contexto, o questionamento surge como uma ferramenta útil na construção de conhecimento e no desenvolvimento destas competências no aluno. Pela relevância que o manual escolar assume nas aulas de Ciências, importa que este contribua positivamente para a competenciação do aluno. Neste pressuposto, foram analisados os manuais mais adotados nos três anos do $3^{\circ}$ ciclo do Ensino Básico, de acordo com a função e localização das questões, assim como o nível cognitivo das mesmas. Apesar de a maioria das questões ser de baixo nível cognitivo, verifica-se a existência de questões de nível elevado, potenciadoras de uma aprendizagem mais autónoma e autorreguladora.
\end{abstract}

Palavras-chave: Ensino das ciências. Questionamento. Aprendizagem baseada na resolução de problemas. Manual escolar. Ciências naturais.

Abstract: Problem Based Learning (PBL) is an Inquiry-Based Learning approach that aims to prompt the development of diverse competences that allow the stimulation of scientific reasoning, autonomy and the development of capacities like questioning and critical reflection. In this context, questioning is a useful tool in students' knowledge construction and in the development of the mentioned competences. As textbooks are important in science classes, they must contribute relevantly to the learning process. Having this in mind, the textbooks most used in 7 th, 8 th and 9 th grades were analyzed according to the function and location of questions, as well as their cognitive level. These textbooks present a different number of questions. Despite the fact that the majority of questions are of low cognitive level (encyclopedic), there are also a considerable number of questions of high cognitive level, which promote a more autonomous and self-regulated learning.

Keywords: Science education. Questioning. Problem-based learning. Textbook. Natural sciences.

\footnotetext{
${ }^{1}$ Unidade de Ensino das Ciências, Instituto de Ciências da Terra, Faculdade de Ciências, Universidade do Porto, Porto, Portugal.

${ }^{2}$ Escola Superior de Educação de Lisboa (ESEL), Lisboa, Portugal.

${ }^{3}$ Departamento de Geociências, Ambiente e Ordenamento do Território, Unidade de Ensino das Ciências, Instituto de Ciências da Terra, Faculdade de Ciências, Universidade do Porto, Rua do Campo Alegre, s/n, 4169007, Porto, Portugal. E-mail: <csvascon@fc.up.pt>
} 


\section{Introdução}

No mundo fortemente marcado pela ciência e pela tecnologia em que vivemos, tornase premente que a escola prepare os alunos para enfrentarem os desafios da nossa sociedade, revelando-se a literacia científica fundamental para um amplo exercício da cidadania. A literacia científica traduz-se pela capacidade de utilizar, de modo apropriado e criativo, as faculdades e o conhecimento científico de forma a resolver problemas próprios, assim como de tomar decisões responsáveis. Desta forma, a formação pessoal, as atitudes e o desenvolvimento de capacidades de interação social, de comunicação, de argumentação e de raciocínio são essenciais para a literacia científica (HOLBROOK; RANNIKMAE, 2009).

A própria Lei de Bases do Sistema Educativo Português (Lei no 49/2005 de 30 de agosto) preconiza que

O sistema educativo responde às necessidades resultantes da realidade social, contribuindo para o desenvolvimento pleno e harmonioso da personalidade dos indivíduos, incentivando a formação de cidadãos livres, responsáveis, autónomos e solidários, [...] capazes de julgarem com espírito crítico e criativo o meio social em que se integram e de se empenharem na sua transformação progressiva. (PORTUGAL, 2005, p. 5125)

O desenvolvimento da autonomia dos alunos, visando a formação de cidadãos civicamente responsáveis e democraticamente intervenientes na vida comunitária surge, assim, como um dos objetivos basilares para o Ensino Básico. Desta forma, as Orientações Curriculares para o $3^{\circ}$ Ciclo do Ensino Básico de Ciências Físicas e Naturais apelam para o desenvolvimento da literacia científica dos alunos e para o desenvolvimento de várias competências, recorrendo-se a diversos ambientes de aprendizagem (PORTUGAL, 2001).

Atualmente, é defendido que os alunos conseguem aprender conteúdos e estratégias de pensamento ao resolverem problemas, sendo a Aprendizagem Baseada na Resolução de Problemas (ABRP) uma metodologia de ensino que se baseia no uso de problemas do quotidiano como ponto de partida para a aprendizagem (VASCONCELOS; ALMEIDA, 2012). Assim, tal como no nosso quotidiano, o problema surge antes de sabermos como o vamos resolver. Os alunos sabem porque estão a aprender, aumentando, assim, a motivação, sendo a informação reunida pelos alunos, numa unidade de estudo, aprendida com o propósito de resolver um problema (CHIN; CHIA, 2004). Com esta metodologia, os alunos refletem sobre o conhecimento abstrato construído e desenvolvem a sua autonomia e as suas competências de comunicação, de pensamento crítico e de tomada de decisões, constituindo a base para a aprendizagem ao longo da vida (VASCONCELOS; ALMEIDA, 2012).

Neste contexto, o questionamento é encarado como uma ferramenta útil e facilitadora da aprendizagem, uma vez que instiga os alunos: a explicitarem o seu conhecimento prévio, a observarem, a estabelecerem relações, a criticarem e a explicarem, contribuindo para o desenvolvimento do aluno (SCHEIN; COELHO, 2006). As questões colocadas pelos alunos levam a que estes se empenhem e desenvolvam a sua capacidade de resolver problemas, respondendo às suas próprias questões. Apesar de toda a importância atribuída às questões formuladas pelos 
alunos, estes não costumam colocar muitas questões, respondendo, essencialmente, às questões formuladas pelos professores ou às existentes nos manuais escolares (MARBACH-AD; SOKOLOVE, 2000). De acordo com a ABRP, as questões que requerem compreensão e um pensamento de ordem superior são as que mais interessam e mais contribuem para o desenvolvimento do aluno. Assim, tal como os professores devem colocar questões que envolvam pensamento de alto nível cognitivo, também os manuais devem incluir esse tipo de questões, uma vez que são os instrumentos mais utilizados na sala de aula (CAMPANARIO; OTERO, 2000).

Segundo Gérard e Roegiers (1998, p. 19), um "manual escolar pode ser definido como um instrumento impresso, intencionalmente estruturado para se inscrever num processo de aprendizagem, com o fim de lhe melhorar a eficácia". Apesar de toda a variedade de materiais pedagógicos disponível atualmente, o manual escolar continua a ser o principal recurso educativo a ser utilizado nas salas de aula, exercendo uma grande influência na aprendizagem dos alunos. De facto, através do manual, os professores orientam e dirigem muitas das atividades em sala de aula, assumindo, os manuais escolares, o estatuto do próprio currículo. Para além disso, os docentes também fazem uso dos manuais escolares como um recurso para os trabalhos de casa dos alunos e como fonte de problemas e perguntas para a avaliação destes (CAMPANARIO; OTERO, 2000).

Para Gérard e Roegiers (1998), os manuais escolares podem desempenhar diversas funções, quer se destinem a alunos, quer a professores. De facto, para os alunos estes desempenham, para além de funções ligadas à aprendizagem (relativas à transmissão de conhecimento, ao desenvolvimento de capacidades e de competências e consolidação e avaliação das aquisições), funções de ligação das aprendizagens à vida quotidiana e profissional (ao nível da integração das aquisições, como referência, e ao nível de uma educação social e cultural). Para os professores, encontram-se, maioritariamente, funções de formação, no sentido de melhorar o seu papel no processo de ensino e aprendizagem. O manual escolar pode, assim, assumir diferentes formas, de acordo com a ênfase atribuída às suas diferentes funções (GÉRARD; ROEGIERS, 1998). No entanto, e "independentemente das funções para as quais o manual é concebido, a finalidade de qualquer manual é, primordialmente, a função de desenvolvimento das competências do aluno e não a simples transmissão de conhecimentos, ao aprendente" (SANTO, 2006. p. 107). Assim, importa explorar de que forma os manuais lidam com o desenvolvimento de competências dos alunos, nomeadamente ao nível do questionamento.

Estudos indicam que muitas das questões incluídas nos manuais não envolvem problemas e apenas requerem pensamento de baixo nível cognitivo, isto é, implicam apenas respostas que requerem informação básica (ALLEN; TANNER, 2002; DOURADO; LEITE, 2010; LEITE et al., 2012). Num estudo realizado por Shepardson e Pizzini (1991 apud DORI; HERSCOVITZ, 1999, p. 426), concluiu-se que as questões dos livros de Ciências enfatizam questões de "nível de inpul" (classificação sugerida pelos autores do estudo referindo-se às questões que apenas requerem que os alunos recordem informação), havendo falta de questões "de processamento" (que requerem que o aluno estabeleça relações entre os conceitos e dados recordados) e de "nível de outpul" (que requerem que os alunos vão mais além do que os próprios dados). Desta forma, os alunos são sujeitos a propósitos de baixo nível cognitivo, sendo a sua atenção restringida apenas à informação textual. No entanto, e apesar da importância de questões de baixo nível cognitivo (funcionando como uma base para processos cognitivos de ordem superior), as questões de elevado nível cognitivo, isto é, que podem ser respondidas apenas 
recorrendo-se a uma investigação, são cruciais no desenvolvimento de capacidades intelectuais complexas (ALLEN; TANNER, 2002; DOURADO; LEITE, 2010).

Desta forma, os manuais escolares merecem especial relevância no que concerne à forma como lidam com o questionamento, enquanto recurso promotor do desenvolvimento desta competência nos alunos e da sua competenciação.

\section{O Questionamento}

A formulação de questões é uma atividade frequente, quer no nosso quotidiano, quer em contexto de sala de aula. Neste último, o questionamento, considerado como a essência do ensino, assume especial relevância, uma vez que suscita desequilíbrios que incitam os alunos a superarem-se, a pesquisarem e a procurarem novas soluções (GIORDAN; VECCHI, 1996; VASCONCELOS et al., 2012). Gall (1987 apud VIEIRA; TENREIRO-VIEIRA, 2005, p. 5657) aponta diversas razões que justificam o recurso ao questionamento, sendo elas: (i) o facto de motivar e envolver os alunos nas tarefas; (ii) de focar a atenção do aluno; (iii) de promover capacidades de pensamento dos alunos; (iv) de ativar processos metacognitivos; (v) de eliciar práticas futuras e avaliação de conteúdos curriculares.

Mesmo sendo o questionamento, pelos professores, comum em bastante número de salas de aula, estes devem procurar colocar questões, preferencialmente, relativas ao quotidiano, que visem a promoção da reflexão e o desenvolvimento do espírito crítico e da criatividade, concedendo tempo suficiente aos alunos para responderem (LOUREIRO, 2008; TORRES; PRETO; VASCONCELOS, 2013). Por outro lado, sendo ainda muito predominante o ensino transmissivo, unidirecional, enciclopédico e mecânico, as questões dos professores são mais de verificação do que o aluno já sabe, sem estabelecer relações com o que estão a aprender e com o que devem procurar resolver. Talvez por isso seja quase sempre muito pouco o tempo que o professor oferece ao seu aluno para responder, antecipando ele mesmo a resposta esperada. Na realidade, o tempo de espera da resposta do aluno após o questionamento pode ser benéfico, uma vez que pode: originar respostas mais longas, mais argumentadas e com maior lógica; aumentar o número de voluntários a participar; reduzir o número de respostas erradas; desenvolver competências de ordem superior, e aumentar o número de questões levantadas pelos alunos (LANG; EVANS, 2006).

Apesar de os professores colocarem diversas questões numa aula, estudos indicam que os estudantes formulam poucas questões e que estas são, geralmente, de baixo nível cognitivo (CUCCIO-SCHIRRIPA; STEINER, 2000; OLIVEIRA, 2008; VASCONCELOS et al., 2012). Se, por um lado, o professor não serve de modelo, por ser detentor de um nível de conhecimentos muito superior aos dos alunos, sabemos, também, que a escola reclama mais a resposta certa do que o levantamento da pergunta oportuna. Talvez, por esta razão, a idade dos porquês termine por volta dos sete anos de idade, altura em que o sistema educativo reclama a presença do aluno na escola... a responder, e não a perguntar. Assim, o levantamento de questões pode não ser uma tarefa fácil para todos os alunos, existindo diversos pormenores que influenciam o levantamento de questões (COSTA et al., 2000), tais como: (i) as falhas em detetar dificuldades, ou seja, dificuldades em "compreender a sua própria compreensão"; (ii) as variáveis pessoais, como a motivação, desempenho e autoestima; (iii) os constrangimentos sociais e os contextos; 
(iv) a forma de avaliação de alguns sistemas educativos, que pode desencorajar os próprios alunos de se questionarem. Contudo, tal como referido por Marbach-Ad e Sokolove (2000), encorajar os alunos a questionarem e a pesquisarem de forma a responderem às suas questões é certamente um caminho para promover a autonomia na aprendizagem.

Embora as questões formuladas pelos discentes sejam escassas, são várias as razões que justificam a necessidade de os encorajar a desenvolver o questionamento (MARBACH-AD; SOKOLOVE, 2000; LOUREIRO, 2008; OLIVEIRA, 2008). Cuccio-Schirripa e Steiner (2000, p. 210) referem que "através do pensamento na competência cognitiva de questionar, o pensamento pode ter o potencial de gerar aprendizagem”. Schein e Coelho (2006) referem que o questionamento, para além de favorecer a explicitação do conhecimento prévio do aluno, promove o desenvolvimento de capacidades e o estabelecimento de relações entre o real e o abstrato, contribuindo para a progressão do aluno para níveis de maior complexidade conceptual. $\mathrm{Na}$ realidade, o levantamento de questões na sala de aula permite que o aluno transforme e exponha o seu pensamento, e que fique com uma melhor compreensão de diversos conceitos, sendo-lhes transmitida a mensagem de que tanto o questionamento como a investigação são processos naturais e essenciais à Ciência (CHIN; KAYALVIZHI, 2002; MARBACH-AD; SOKOLOVE, 2000). Ao colocarem questões, os alunos podem também fornecer, aos professores, as suas ideias preconcebidas e conceções alternativas (CHIN; CHIA, 2004), facilitando o processo de ensino e aprendizagem. Adicionalmente, os alunos ficam mais entusiasmados quando procuram respostas às questões por eles próprios colocadas (CHIN; KAYALVIZHI, 2002).

Apesar de toda a importância atribuída ao questionamento pelos alunos, ao iniciarem o seu processo escolar, estes, como já referido anteriormente, vão aprendendo a diminuir o número de questões, uma vez que os professores não estimulam o questionamento (MARBACH-AD; SOKOLOVE, 2000). Muitos professores, especialmente os que se consideram como distribuidores de conhecimento (CHIN; KAYALVIZHI, 2002), evitam o confronto com as questões dos alunos, uma vez que estas podem extravasar a esfera do conhecimento do próprio professor (WATTS; ALSOP, 1995 apud CHIN; KAYALVIZHI, 2002, p. 271). Apesar de todas estas condicionantes, algumas investigações indicam que os alunos conseguem colocar muitas questões, quando lhes é dada a oportunidade para tal (COSTA et al., 2000), sendo também possível que formulem maior quantidade de questões de nível elevado, se lhes forem dadas oportunidades de desenvolverem competências de formulação de questões (OLIVEIRA, 2008; LEITE et al., 2012).

Pelo exposto, importa que a escola fomente o aperfeiçoamento da capacidade de indagação dos alunos, de modo a que estes coloquem questões de elevado nível cognitivo, desenvolvendo o seu pensamento crítico e a capacidade de resolver problemas (MARBACH-AD; SOKOLOVE, 2000).

Dada a relevância do questionamento no ensino e na aprendizagem, importa analisar as questões e o seu potencial em todo este processo. Do ponto de vista da competenciação do aluno, as perguntas mais relevantes a desenvolver numa sala de aula são as perguntas de nível cognitivo elevado, cuja resposta requer reflexão e compreensão dos assuntos (DOURADO; LEITE, 2010).

São várias as taxonomias existentes para classificar as questões, sendo a taxonomia de Bloom, da década de 50 do século XX, um exemplo (BLOOM et al., 1956). Esta taxonomia é uma das mais comuns e permitiu ajudar os professores a relacionarem as questões que colocam 
com o tipo de capacidades de pensamento que pretendem que os alunos desenvolvam, sendo uma ferramenta útil na distinção entre conhecimento e pensamento de baixo nível cognitivo e de alto nível cognitivo (ALLEN; TANNER, 2002).

Dahlgren e Öberg (2001), por sua vez, realizaram um estudo no qual avaliaram o tipo de questões que alunos de licenciatura, na disciplina de Educação Ambiental, colocaram perante diversos cenários. Assim, desenvolveram uma taxonomia, na qual as questões foram classificadas em: (i) Questões Enciclopédicas - que se caracterizam por requererem uma resposta simples e não ambígua, podendo ser respondidas com "Sim" ou "Não" ou com uma definição (exemplo: Qual é o objeto de estudo dos Geólogos?); (ii) Questões de Compreensão - que se orientam pela procura do significado fenomenológico de certos termos e conceitos, implicando a procura de um significado para um dado conceito (exemplo: Por que razão se manifestam os vulcões de modos tão diferentes?); (iii) Questões Relacionais - que são relativas a diversos aspetos e com a relação entre eles, pretendendo explicar causas ou consequências de fenómenos (exemplo: Qual a influência das condições de solidificação no desenvolvimento dos minerais?); (iv) Questões de Avaliação - que requerem um juízo de valor, envolvendo comparações (exemplo: Que tipos de fontes de energia são bons/maus para o ambiente?); (v) Questões de Procura de Solução - que lidam com problemas abrangentes e complexos, sendo que a resposta requer a resolução de um problema (exemplo: Como podemos alterar o nosso comportamento de forma a alcançarmos um desenvolvimento global sustentável?).

Chin e Chia (2004), num estudo apoiado na metodologia da ABRP, analisaram as questões colocadas pelos alunos, quer individualmente, quer em grupo, classificando-as em: (i) Questões de Informação Básica, comparáveis às Questões Enciclopédicas de Dahlgren e Öberg (2001); (ii) Questões de Explicações, comparáveis às Questões Relacionais das mesmas autoras; (iii) Questões de Cenários Imaginários, comparáveis às Questões de Aplicação referenciadas por Allen e Tanner (2002). Muitos outros estudos foram efetuados, quer na análise de questões efetuadas pelos alunos ou pelos professores, quer na análise de questões existentes nos manuais escolares, dando origem a diversas taxonomias. No entanto, estudos realizados por Loureiro (2008) e Oliveira (2008) demonstram que "[...] apesar das inicialmente aparentes grandes diferenças (em termos de quantidades de tipos considerados e de designações adotadas) entre as diversas tipologias de questões, acaba por haver bastantes coincidências entre elas" (LOUREIRO, 2008, p. 36).

De uma forma geral, também se podem agrupar as diferentes tipologias de questões em duas categorias mais amplas, de acordo com o grau de envolvimento cognitivo dos alunos: as questões de nível cognitivo de ordem inferior e as de ordem superior (HOFSTEIN et al., 2005). Desta forma, as questões de nível cognitivo de ordem inferior implicam respostas que requerem informação mais básica, podendo ser uma única palavra ou explicação; e as de ordem superior apenas podem ser respondidas recorrendo-se a uma investigação ulterior, sendo necessária a elaboração de respostas mais complexas, que induzem os alunos à reflexão crítica e à articulação de conteúdos.

No contexto atual de Educação em Ciências e de um ensino orientado para a ABRP, as questões mais relevantes são as de nível cognitivo de ordem superior (DOURADO; LEITE, 2010), que promovem o desenvolvimento de capacidades de pensamento que exigem raciocínio metacognitivo, como, por exemplo, estabelecer avaliações e decisões. 


\section{Metodologia}

Neste estudo é analisada a forma como os manuais de Ciências Naturais, do $3^{\circ}$ ciclo do Ensino Básico (do $7^{\circ}$ ao $9^{\circ}$ ano de escolaridade), lidam com o questionamento, aferindo se este se adequa ao preconizado pela ABRP e pelas próprias Orientações Curriculares.

Para atingir o objetivo deste estudo, foram analisados os três manuais de Ciências Naturais, do $3^{\circ}$ ciclo do Ensino Básico, mais adotados no ano letivo 2011/2012. A análise focou-se nas questões incluídas nos manuais de Ciências Naturais referidos (C7 - manual mais vendido para o $7^{\circ}$ ano; $\mathrm{C} 8$ - manual mais vendido para o $8^{\circ}$ ano; $\mathrm{C} 9$ - manual mais vendido para o $9^{\circ}$ ano), não sendo consideradas as perguntas utilizadas em atividades de avaliação final, nem as contempladas dentro de uma atividade. Relativamente à exigência cognitiva das questões, estas foram analisadas de acordo com uma adaptação da taxonomia de Dahlgren e Öberg (2001), uma vez que foi necessária a inclusão da categoria “Questões de Cenários Imaginários”, proposta por Chin e Chia (2004). Paralelamente, optou-se por se utilizar outras dimensões de análise, desenvolvidas por Dourado e Leite (2010), relativas à localização no manual, à função da questão e à apresentação da resposta à questão.

\section{Análise dos resultados}

Por meio da análise dos manuais do $3^{\circ}$ ciclo do Ensino Básico, adotados por mais escolas, verifica-se que estes apresentam um número muito variado de questões. O livro que contém mais questões é o de $9^{\circ}$ ano (121 questões), sendo este número muito superior ao número de questões existentes no livro de $7^{\circ}$ ano ( 37 questões) e no livro de $8^{\circ}$ ano de escolaridade ( 22 questões).

No que diz respeito à localização das questões nos manuais (Tabela 1), estas localizamse, essencialmente, no título das secções, destacando-se o manual de $9^{\circ}$ ano com $88,4 \%$ das suas questões nesta localização.

Neste caso, as questões poderão servir como fator de motivação para os alunos, estimulando-os a procurarem informação sobre o conteúdo a ser tratado ao longo da unidade programática. A partir destes títulos, os alunos poderão tentar relacionar o seu conhecimento e o seu quotidiano com a própria questão, percebendo qual a utilidade do conhecimento que será apresentado.

No exemplo exposto na Figura 1, é apresentada uma questão no título da secção: "Por que aumenta o batimento cardíaco em determinadas situações?". Esta questão poderá despertar interesse nos alunos e ativar ligações com o seu dia a dia e com outras aprendizagens. Posteriormente, é dada a resposta no texto e fornecida uma imagem explicativa complementar, que servirá para consolidar as aprendizagens ou auxiliar na reconceptualização cognitiva. Assumem, também, alguma relevância as questões que se encontram na abertura do tema $(8,3 \%)$ e da unidade (4,4\%). Da mesma forma, estas incentivam os alunos para o estudo do tema e/ ou unidade, referindo o que estes irão aprender. Apesar do grande número de questões que o manual de $9^{\circ}$ ano apresenta, este apenas contém questões de abertura de tema e de unidade e de título de secções. 
Torres, J.; Almeida, A.; Vasconcelos, C.

Tabela 1. Localização das questões nos manuais

\begin{tabular}{|c|c|c|c|c|c|c|c|c|}
\hline \multirow[t]{2}{*}{ Local } & \multicolumn{2}{|c|}{ C7 } & \multicolumn{2}{|c|}{$\mathrm{C} 8$} & \multicolumn{2}{|c|}{ C9 } & \multicolumn{2}{|c|}{ Total } \\
\hline & f & $\%$ & $f$ & $\%$ & f & $\%$ & $\mathrm{f}$ & $\%$ \\
\hline Abertura do tema & 6 & 16,2 & 3 & 13,6 & 6 & 5,0 & 15 & 8,3 \\
\hline Abertura da unidade & 0 & 0 & 0 & 0 & 8 & 6,6 & 8 & 4,4 \\
\hline Abertura da subunidade & 3 & 8,1 & 0 & 0 & 0 & 0 & 3 & 1,7 \\
\hline Título das secções & 21 & 56,8 & 14 & 63,6 & 107 & 88,4 & 142 & 78,9 \\
\hline \multicolumn{9}{|l|}{ Ao longo do texto } \\
\hline De Ligação & 1 & 2,7 & 0 & 0 & 0 & 0 & 1 & 0,6 \\
\hline De aplicação & 1 & 2,7 & 0 & 0 & 0 & 0 & 1 & 0,6 \\
\hline Associadas a atividades & & & & & 0 & 0 & 4 & 2,2 \\
\hline No título & 2 & 5,4 & 2 & 9,1 & & & & \\
\hline $\mathrm{Na}$ formulação da atividade & 2 & 5,4 & 3 & 13,6 & 0 & 0 & 5 & 2,8 \\
\hline No final da subunidade & 1 & 2,7 & 0 & 0 & 0 & 0 & 1 & 0,6 \\
\hline No final do tema & 0 & 0 & 0 & 0 & 0 & 0 & 0 & 0 \\
\hline Total de Questões & 37 & 100 & 22 & 100 & 121 & 100 & 180 & 100 \\
\hline
\end{tabular}

Legenda: C7 - manual mais vendido para o $7^{\circ}$ ano; C8 - manual mais vendido para o $8^{\circ}$ ano; C9 - manual mais vendido para o $9^{\circ}$ ano.

Fonte: adaptada de Dourado e Leite (2010).

Figura 1. Exemplo de questão no título da secção

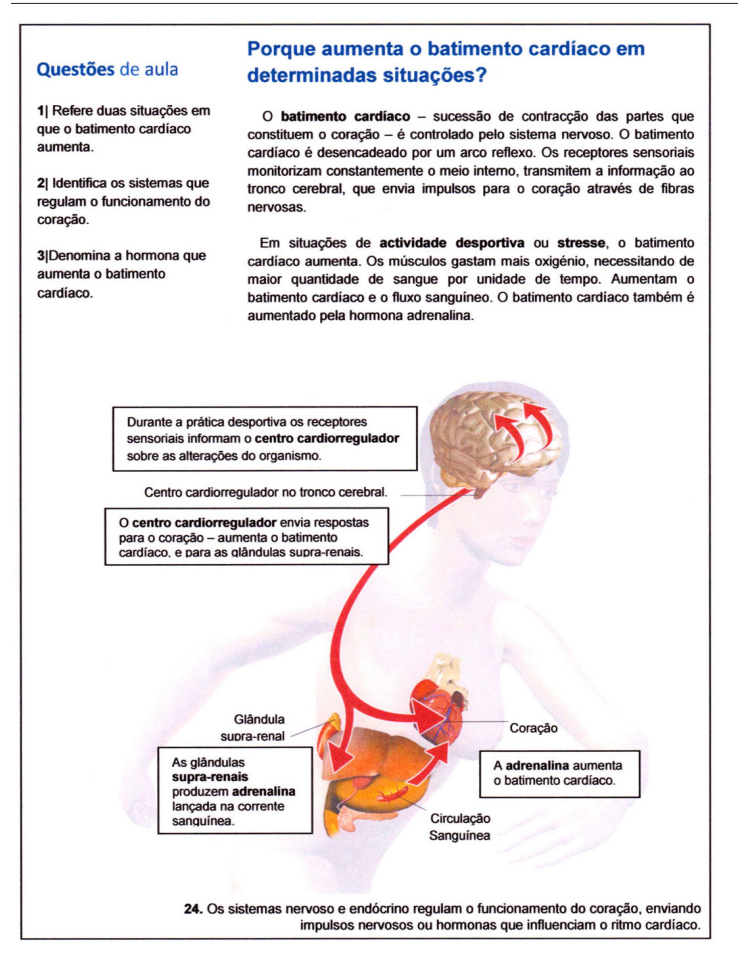

Fonte: Adaptado do manual escolar C9. 
Em contrapartida, os manuais de $7^{\circ}$ e $8^{\circ}$ anos apresentam ainda um número considerável de questões associadas a atividades, tanto no título da atividade $(2,2 \%)$, como na própria formulação da atividade $(2,8 \%)$. Os títulos das atividades permitem enquadrar o aluno na atividade em si e no seu propósito, motivando-o para a sua resolução (Figura 2).

Figura 2. Exemplo de questão no título da atividade

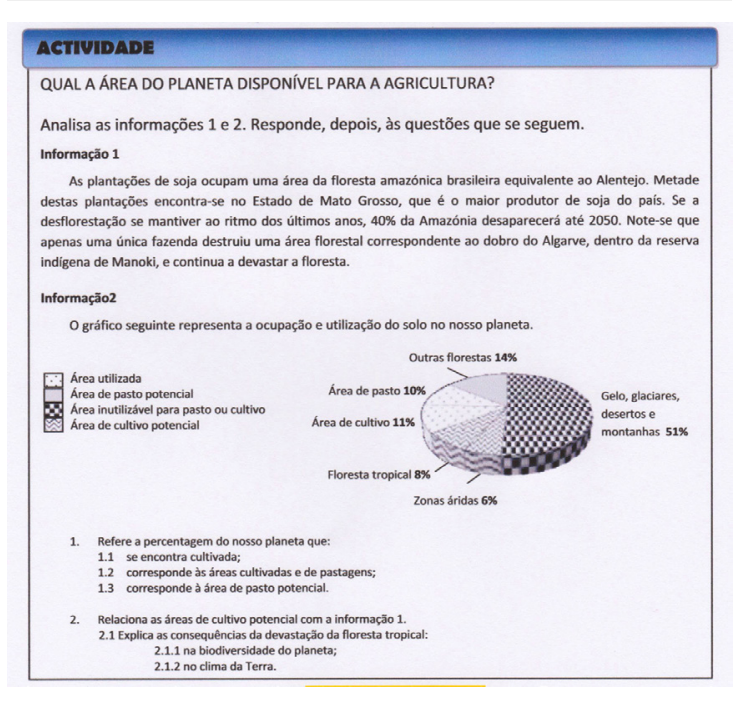

Fonte: Adaptado do manual escolar C8.

Nas atividades em que a própria questão dirige toda a tarefa, os alunos são incitados a pensarem no procedimento a adotar, a colocarem hipóteses e, a partir dos resultados, a responderem à questão-problema. No exemplo apresentado (Figura 3), os alunos planificam o procedimento, registam e discutem os resultados, de forma a responderem à questão-problema inicial "A luz influencia o desenvolvimento das plantas?". Neste caso, os alunos podem (não significando que o façam) desenvolver a sua autonomia e espírito crítico, tendo um papel ativo na construção da sua aprendizagem.

Relativamente às questões associadas à formulação da atividade, destaca-se, ainda, no manual de $8^{\circ}$ ano, uma proposta em que os alunos são solicitados a tomarem uma decisão, de forma a responderem a uma questão-problema relacionada com o quotidiano. Mais uma vez, os alunos são solicitados a articularem conhecimentos, a desenvolverem o seu espírito crítico e a tomarem decisões conscientes, informadas e responsáveis, sendo requerida uma avaliação, assim como a aprendizagem de novos conhecimentos.

No que diz respeito à função das questões (Tabela 2), verifica-se que estas surgem, essencialmente, para apresentar o texto a ser desenvolvido $(78,9 \%)$ e para apresentar resultados de aprendizagem esperados $(8,3 \%)$, contribuindo para a motivação do aluno e para uma certa organização do que vai ser aprendido. 
Figura 3. Exemplo de questão na formulação da atividade

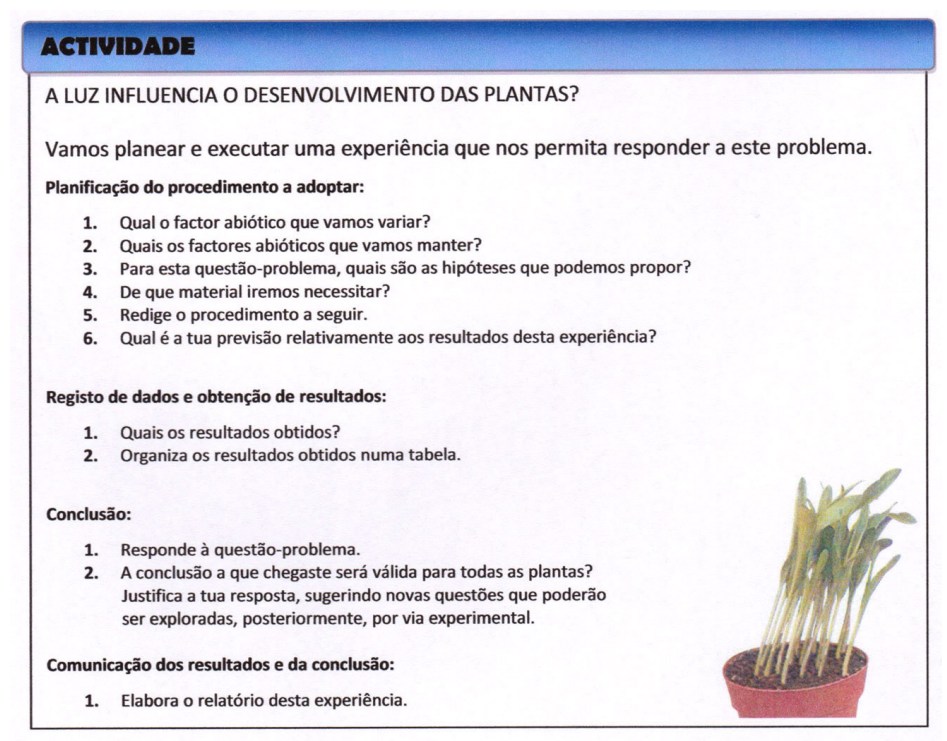

Fonte: Adaptado do manual escolar C8.

Tabela 2. Função das questões nos manuais

\begin{tabular}{|c|c|c|c|c|c|c|c|c|}
\hline \multirow[t]{2}{*}{ Função das questões } & \multicolumn{2}{|c|}{ C7 } & \multicolumn{2}{|c|}{ C8 } & \multicolumn{2}{|c|}{ C9 } & \multicolumn{2}{|c|}{ Total } \\
\hline & f & $\%$ & f & $\%$ & f & $\%$ & f & $\%$ \\
\hline $\begin{array}{l}\text { Apresentar resultados de aprendizagem } \\
\text { esperados }\end{array}$ & 6 & 16,2 & 3 & 13,6 & 6 & 5,0 & 15 & 8,3 \\
\hline Diagnosticar conhecimentos prévios & 0 & 0 & 0 & 0 & 8 & 6,6 & 8 & 4,4 \\
\hline Apresentar o texto a ser desenvolvido & 21 & 56,8 & 14 & 63,6 & 107 & 88,4 & 142 & 78,9 \\
\hline Questão de Ligação & 5 & 13,5 & 0 & 0 & 0 & 0 & 5 & 2,8 \\
\hline \multicolumn{9}{|l|}{ Apresentar atividades de aprendizagem } \\
\hline Facultativa & 1 & 2,7 & 1 & 4,5 & 0 & 0 & 2 & 1,1 \\
\hline Obrigatória & 4 & 10,8 & 4 & 18,2 & 0 & 0 & 8 & 4,4 \\
\hline Proposta & 0 & 0 & 0 & 0 & 0 & 0 & 0 & 0 \\
\hline \multicolumn{9}{|l|}{ Aplicação de conhecimentos } \\
\hline Facultativa & 0 & 0 & 0 & 0 & 0 & 0 & 0 & 0 \\
\hline Obrigatória & 0 & 0 & 0 & 0 & 0 & 0 & 0 & 0 \\
\hline Proposta & 0 & 0 & 0 & 0 & 0 & 0 & 0 & 0 \\
\hline
\end{tabular}

Legenda: $\mathrm{C} 7$ - manual mais vendido para o $7^{\circ}$ ano; $\mathrm{C} 8$ - manual mais vendido para o $8^{\circ}$ ano; $\mathrm{C} 9$ - manual mais vendido para $\mathrm{o} 9^{\circ}$ ano.

Fonte: adaptada de Dourado e Leite (2010) .

Apenas o manual de $9^{\circ}$ ano apresenta questões que pretendem diagnosticar conhecimentos prévios; e somente o de $7^{\circ}$ ano apresenta questões de ligação (Figura 4). Estas questões (de ligação) despertam e envolvem os alunos, uma vez que suscitam a sua curiosidade, podendo, 
mesmo, espoletar o desejo de responder à questão e de saber mais, tornando a leitura do manual, assim como a procura de mais informação, mais apelativas.

Figura 4. Exemplo de questão de ligação

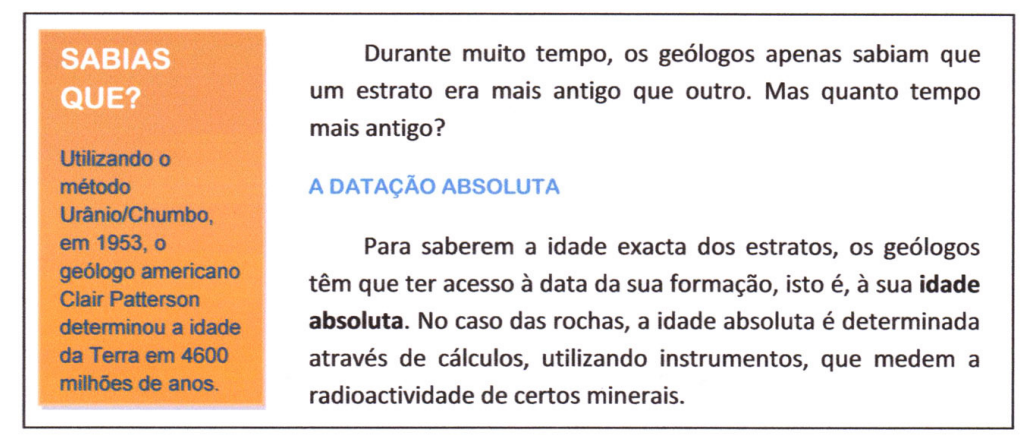

Fonte: Adaptada do manual escolar C7.

No exemplo exposto, a questão "Mas quanto tempo mais antigo?" surge para ligar o texto, relacionando dois conceitos ligados à datação dos estratos, cativando o aluno a saber mais. O intuito desta questão não é fazer com que o aluno a responda, mas, sim, motivá-lo a continuar a leitura, de forma a familiarizar-se com o conceito de datação absoluta.

No que concerne às respostas às questões (Tabela 3), verifica-se que 95,6\% das respostas são fornecidas no manual, havendo apenas três questões sem qualquer resposta. Na maioria, as respostas às questões são dadas de um modo explícito e completo.

Tabela 3. Resposta às questões nos manuais

\begin{tabular}{lcccc}
\hline \multicolumn{1}{c}{ Resposta } & C7 & C8 & C9 & Total \\
\hline Ignorada & 0 & 0 & 3 & 3 \\
Fornecida & & & & \\
$\quad$ Explicitamente & 25 & 15 & 107 & 147 \\
$\quad$ Completa & 3 & 0 & 6 & 9 \\
$\quad$ Parcial & & & & \\
$\quad$ Implicitamente & 4 & 4 & 1 & 9 \\
$\quad$ Completa & 3 & 0 & 4 & 7 \\
$\quad$ Parcial & & & & \\
Solicitada ao aluno & 0 & 0 & 0 & 0 \\
$\quad$ Sem orientação da resposta & 0 & 0 & 0 & 0 \\
$\quad$ Com orientação ao nível do conteúdo/estrutura da resposta & 0 & \\
$\quad$ Com orientação ao nível de o que fazer para obter a resposta & 2 & 3 & 0 & 5 \\
\hline
\end{tabular}

Legenda: C7 - manual mais vendido para o $7^{\circ}$ ano; $\mathrm{C} 8$ - manual mais vendido para o $8^{\circ}$ ano; $\mathrm{C} 9$ - manual mais vendido para o $9^{\circ}$ ano.

Fonte: adaptada de Dourado e Leite (2010) . 
Quanto ao nível cognitivo das questões (Tabela 4), a maioria destas é de cariz enciclopédico, ou seja, de baixo nível cognitivo. No entanto, verifica-se uma percentagem considerável de questões de compreensão e questões relacionais. O manual de $7^{\circ}$ ano é o que apresenta uma maior percentagem de questões enciclopédicas; o manual de $8^{\circ}$, de questões de compreensão, e o de $9^{\circ}$, de questões enciclopédicas e de compreensão (em igual número).

Tabela 4. Nível Cognitivo das Questões nos Manuais

\begin{tabular}{|c|c|c|c|c|c|c|c|c|}
\hline \multirow[t]{2}{*}{ Categoria } & \multicolumn{2}{|c|}{ C7 } & \multicolumn{2}{|c|}{ C8 } & \multicolumn{2}{|c|}{ C9 } & \multicolumn{2}{|c|}{ Total } \\
\hline & $\mathrm{f}$ & $\%$ & $f$ & $\%$ & $\mathrm{f}$ & $\%$ & $\mathrm{f}$ & $\%$ \\
\hline Enciclopédica & 28 & 75,7 & 8 & 36,4 & 52 & 43,0 & 88 & 48,9 \\
\hline Compreensão & 4 & 10,8 & 10 & 45,5 & 52 & 43,0 & 66 & 36,7 \\
\hline Relacional & 2 & 5,4 & 1 & 4,5 & 15 & 12,4 & 18 & 10,0 \\
\hline Avaliação & 1 & 2,7 & 3 & 13,6 & 1 & 0,8 & 5 & 2,8 \\
\hline Procura de Solução & 0 & 0 & 0 & 0 & 1 & 0,8 & 1 & 0,6 \\
\hline Cenários Imaginários & 1 & 2,7 & 0 & 0 & 0 & 0 & 1 & 0,6 \\
\hline Sem classificação & 1 & 2,7 & 0 & 0 & 0 & 0 & 1 & 0,6 \\
\hline
\end{tabular}

Legenda: C7 - manual mais vendido para o $7^{\circ}$ ano; C8 - manual mais vendido para o $8^{\circ}$ ano; $\mathrm{C} 9$ - manual mais vendido para o $9^{\circ}$ ano.

Fonte: adaptada de Dahlgren e Öberg (2001).

No Quadro 1, são dados exemplos de cada tipo de questão existentes em cada manual.

Ao analisar a categoria das questões em função da localização das mesmas (Tabela 5), verifica-se que tanto ao nível da abertura do tema, como ao nível da abertura das unidades ou subunidades, apenas se encontram questões enciclopédicas ou de compreensão, havendo uma maior percentagem de questões de compreensão. No entanto, verifica-se que o manual de $7^{\circ}$ ano apenas apresenta uma questão de compreensão, sendo todas as outras questões de caráter enciclopédico, ou seja, de baixo nível cognitivo, não promovendo a aplicação e mobilização de conhecimentos. Já o manual de $8^{\circ}$ ano apenas apresenta questões de compreensão, e o de $9^{\circ}$ uma percentagem considerável deste tipo de questões, sendo, desta forma, requerida uma maior mobilização de conhecimentos. No que concerne aos títulos de secções, já se encontram questões de diversas categorias, com uma maior percentagem de questões enciclopédicas e de compreensão. É de realçar que todos os manuais possuem, para além de questões enciclopédicas, questões de compreensão, relacionais e de avaliação que desempenham um papel fundamental na aprendizagem. Nesta localização, o manual de $9^{\circ}$ ano possui apenas uma questão de procura de solução, embora seja o único a possuir questões desta categoria. Este tipo de questão é especialmente relevante para o desenvolvimento do aluno num contexto da ABRP, uma vez que se pretende que este encontre uma solução para um problema que, neste caso, está relacionado com a sociedade, ao mesmo tempo que aprende e desenvolve competências.

As questões associadas a atividades são, maioritariamente, enciclopédicas, não sendo muito relevantes, uma vez que não promovem a mobilização de conhecimentos. Apesar das ques- 
Quadro 1. Exemplos de cada tipo de Questões nos Manuais e sua expressão

\begin{tabular}{|c|c|c|c|c|}
\hline & $\begin{array}{c}\text { Enciclopédica }(\mathbf{7 5 , 7 \% )} \\
\text { Onde se encontra o centro do } \\
\text { Universo? }\end{array}$ & $\begin{array}{l}\text { Compreensão } \\
(\mathbf{1 0 , 8 \% )} \\
\text { Como se tornou }\end{array}$ & $\begin{array}{l}\text { Relacional }(\mathbf{5 , 4 \% )} \\
\text { Mas, por que raz̃ão a } \\
\text { crusta oceânica é mais }\end{array}$ & $\begin{array}{l}\text { Avaliação }(\mathbf{2 , 7} \%) \\
\text { Terá o vulcanismo apenas } \\
\text { efeitos negativos? }\end{array}$ \\
\hline C7 & O que são fósseis? & $\begin{array}{c}\text { conhecimento do } \\
\text { Universo? }\end{array}$ & continental? & $\begin{array}{l}\text { Cenários Imaginários } \\
(\mathbf{2 , 7 \% )} \\
\text { Quais serão os próximos passos } \\
\text { ou as próximas descobertas? }\end{array}$ \\
\hline C8 & $\begin{array}{c}\text { Compreensão } \mathbf{( 4 5 , 5 \% )} \\
\text { Por que razão estão os } \\
\text { ecossistemas em equilíbrio } \\
\text { dinâmico? }\end{array}$ & $\begin{array}{l}\text { Enciclopédica } \\
\quad(36,4 \%) \\
\text { O que são } \\
\text { recursos naturais? }\end{array}$ & $\begin{array}{c}\text { Avaliação (13,6\%) } \\
\text { Mas as inovações científicas } \\
\text { e tecnológicas são boas ou } \\
\text { más para a bumanidade? }\end{array}$ & $\begin{array}{c}\text { Relacional }(4,5 \%) \\
\text { Como interagem os seres vivos } \\
\text { com o Ambiente? }\end{array}$ \\
\hline \multirow{2}{*}{ C9 } & $\begin{array}{c}\text { Enciclopédica }(\mathbf{4 3 , 0} \%) \\
\text { O que significa qualidade } \\
\text { de vida? }\end{array}$ & \multirow{2}{*}{$\begin{array}{c}\text { Relacional } \\
(\mathbf{1 2 , 4 \% )} \\
\text { Quais as possíveis } \\
\text { consequências da } \\
\text { manipulação do } \\
\text { material genético? }\end{array}$} & $\begin{array}{l}\text { Avaliação } \mathbf{( 0 , 8 \% )} \\
\text { Como se distingue } \\
\text { alimento de nutriente? }\end{array}$ & \\
\hline & $\begin{array}{c}\text { Compreensão }(\mathbf{4 3}, \mathbf{0} \%) \\
\text { Como ocorrem os ciclos } \\
\text { ovárico e uterino? }\end{array}$ & & $\begin{array}{c}\text { Procura de Soluçãa } \\
\mathbf{( 0 , 8 \% )} \\
\text { Como promover a saúde } \\
\text { comunitária? }\end{array}$ & \\
\hline
\end{tabular}

Legenda: C7 - manual mais vendido para o $7^{\circ}$ ano; $\mathrm{C} 8$ - manual mais vendido para o $8^{\circ}$ ano; $\mathrm{C} 9$ - manual mais vendido para o $9^{\circ}$ ano.

Fonte: Elaborada pelos autores.

tões mencionadas serem maioritariamente enciclopédicas, os alunos são, como já anteriormente referido, por vezes, solicitados a desenvolverem um procedimento experimental. Contudo, este tipo de formulação não se mostra adequado para estimular, nos alunos, o raciocínio científico e o espírito crítico. Deste modo, apesar de a intenção ser promover o desenvolvimento de capacidades investigativas, autonomamente e potenciando a autorregulação, o próprio baixo nível cognitivo da questão não incentiva os alunos nesse processo. Assim, consideramos que as questões que antecedem os trabalhos práticos deveriam ter um nível cognitivo superior.

No manual de $7^{\circ}$ ano, há uma questão de Cenários Imaginários, ou seja, que é relativa ao que poderá acontecer no futuro - "Quais serão os próximos passos ou as próximas descobertas?”. Esta questão pretende deixar os alunos curiosos, instigando-os a procurarem informação e a manterem-se atualizados. 
Tabela 5. Categoria das questões em função da sua localização

\begin{tabular}{|c|c|c|c|c|c|c|c|c|c|}
\hline \multirow{2}{*}{$\begin{array}{l}\text { Localização } \\
\text { das questões }\end{array}$} & \multirow[t]{2}{*}{ Categoria } & \multicolumn{2}{|c|}{ C7 } & \multicolumn{2}{|c|}{$\mathrm{C} 8$} & \multicolumn{2}{|c|}{ C9 } & \multicolumn{2}{|c|}{ Total } \\
\hline & & $\mathrm{f}$ & $\%$ & $f$ & $\%$ & $f$ & $\%$ & $f$ & $\%$ \\
\hline \multirow[t]{2}{*}{ Abertura do Tema } & Enciclopédica & 5 & 83,3 & 0 & 0 & 2 & 33,3 & 7 & 46,7 \\
\hline & Compreensão & 1 & 16,7 & 3 & 100 & 4 & 66,7 & 8 & 53,3 \\
\hline \multirow{2}{*}{$\begin{array}{l}\text { Abertura da Unidade } \\
\text { ou Subunidade }\end{array}$} & Enciclopédica & 3 & 100 & 0 & 0 & 2 & 25,0 & 5 & 45,5 \\
\hline & Compreensão & 0 & 0 & 0 & 0 & 6 & 75,0 & 6 & 54,5 \\
\hline \multirow[t]{5}{*}{ Título da Secção } & Enciclopédica & 16 & 76,2 & 4 & 28,6 & 48 & 44,9 & 68 & 47,9 \\
\hline & Compreensão & 3 & 14,3 & 7 & 50,0 & 42 & 39,3 & 52 & 36,6 \\
\hline & Relacional & 1 & 4,8 & 1 & 7,1 & 15 & 14,0 & 17 & 12,0 \\
\hline & Avaliação & 1 & 4,8 & 2 & 14,3 & 1 & 0,9 & 4 & 2,8 \\
\hline & Procura de Solução & 0 & 0 & 0 & 0 & 1 & 0,9 & 1 & 0,7 \\
\hline \multirow[t]{2}{*}{ Ao longo do texto } & Relacional & 1 & 100 & 0 & 0 & 0 & 0 & 1 & 100 \\
\hline & Sem classificação & 1 & - & 0 & 0 & 0 & 0 & 1 & - \\
\hline No título da atividade & Enciclopédica & 2 & 100 & 2 & 100 & 0 & 0 & 4 & 100 \\
\hline \multirow[t]{2}{*}{$\mathrm{Na}$ formulação da atividade } & Enciclopédica & 2 & 100 & 2 & 66,7 & 0 & 0 & 4 & 80,0 \\
\hline & Avaliação & 0 & 0 & 1 & 33,3 & 0 & 0 & 1 & 20,0 \\
\hline No final da subunidade & Cenários Imaginários & 1 & 100 & 0 & 0 & 0 & 0 & 1 & 100 \\
\hline
\end{tabular}

Legenda: C7 - manual mais vendido para o $7^{\circ}$ ano; $\mathrm{C} 8$ - manual mais vendido para o $8^{\circ}$ ano; $\mathrm{C} 9$ - manual mais vendido para o $9^{\circ}$ ano.

Fonte: Adaptado de Dourado e Leite (2010).

\section{Conclusões}

Por meio da análise dos manuais, verificou-se que estes apresentavam um número muito diversificado de questões, destacando-se o manual de $9^{\circ}$ ano com 121 questões. Constatou-se, também, que a maioria das questões se localizava nos títulos das secções, apresentando o conteúdo a ser desenvolvido, organizando os alunos no processo de autorregulação da aprendizagem e pretendendo motivar ou, simplesmente, constituir um desafio. Contudo, verifica-se que só algumas questões são formuladas para facilitarem o raciocínio e procurarem obter a resposta pelos alunos. Muitas das questões servem apenas para propor uma nova temática a estudar, tornando o manual pouco dirigido para a ABRP e, consequentemente, não promovendo a competenciação do aluno. Por outro lado, algumas questões associadas à formulação da atividade são de nível cognitivo tão baixo, que podem desmotivar o aluno a realizar um esforço crítico e científico capaz de o auxiliar na consecução da tarefa.

Relativamente às respostas às questões, apenas 3 questões de um manual de $9^{\circ}$ ano não apresentam qualquer resposta. Grande parte das respostas às questões é fornecida explicitamente e de forma completa. Quando as respostas são solicitadas ao aluno, são apresentadas as orientações ao nível do que fazer para obter a solução.

Apesar de grande parte das questões serem de nível enciclopédico, ou seja, de baixo nível cognitivo, verifica-se uma percentagem considerável dos outros tipos de questões (de elevado nível cognitivo). O manual de $7^{\circ}$ ano é o que apresenta um maior número de questões enciclopédicas, podendo este facto estar associado ao nível etário dos alunos. 
Pelo exposto, consideramos que a escolha dos manuais pelos professores deve ter em conta o nível cognitivo das questões, de modo a que estas não sejam de resposta óbvia, mecânica ou memorística. Numa Aprendizagem orientada para a Investigação, pretende-se estabelecer um questionamento que espelhe o trabalho do cientista e, por isso, estimule o aluno: a procurar explicações (possíveis hipóteses), a desenvolver um raciocínio lógico, e a ser capaz de encontrar as respostas que o permitam argumentar com evidências às questões.

\section{Referências}

ALLEN, D.; TANNER, K. Approaches to cell biology teaching: questions about questions. Cell Biology Education, Bethesda, v. 1, n. 3, p. 63-67, 2002. Disponível em: < http:/ / dx.doi.org/10.1187/cbe.02-07-0021>. Acesso em: 19 maio 2015.

BLOOM, B. S. et al. Taxonomy of educational objectives. New York: David McKay, 1956. (Handbook 1: cognitive domain).

CAMPANARIO, J. M.; OTERO, J. La comprensión de los libros de texto. In: PERALES, F. J.; PORLAN, R. (Ed.). Didática de las ciencias experimentales. Alcoy: Editorial Marfil, 2000. p. 323-338.

CHIN, C.; CHIA, L. G. Problem-based learning: using students' questions to drive knowledge construction. Science Education, Hoboken, v. 88, n. 5, p. 707-727, 2004.

CHIN, C.; KAYALVIZHI, G. Posing problems for open investigations: what questions do pupils ask? Research in Science \& Technological Education, Abingdon, v. 20, n. 2, p. 269-287, 2002.

COSTA, J. et al. An analysis of question asking on scientific texts explaining natural phenomena. Journal of Research in Science Teaching, Hoboken, v. 37, n. 6, p. 602-614, 2000 .

CUCCIO-SCHIRRIPA, S.; STEINER, H. E. Enhancement and analysis of science question level for middle school students. Journal of Research in Science Teaching, Hoboken, v. 37, n. 2, p. 210-224, 2000.

DAHLGREN, M. A.; ÖBERG, G. Questioning to learn and learning to question: structure and function of problem-based learning scenarios in environmental science education.

Higher Education, Dordrecht, v. 41, n. 3, p. 263-282, 2001.

DORI, Y. J.; HERSCOVITZ, O. Question-posing capability as an alternative evaluation method: analysis of an environmental case study. Journal of Research in Science Teaching, Hoboken, v. 36, n. 4, p. 411-430, 1999.

DOURADO, L.; LEITE, L. Questionamento em manuais escolares de ciências: que contributos para a aprendizagem baseada na resolução de problemas da "sustentabilidade na Terra”? In: CONGRESO DE ENCIGA, 23., 2010, A Coruña. Actas... Disponível em: <http:/ / repositorium.sdum.uminho.pt/handle/1822/11295>. Acesso em: 19 maio 2015. 
GÉRARD, F; ROEGIERS, X. Conceber e avaliar manuais escolares. Porto: Porto Editora, 1998.

GIORDAN, A.; VECCHI, G. As origens do saber: das concepções dos aprendentes aos conceitos científicos. Porto Alegre: Artes Médicas, 1996.

HOFSTEIN, A. et al. Developing students' ability to ask more and better questions resulting from inquiry-type chemistry laboratories. Journal of Research in Science Teaching, Hoboken, v. 42, n. 7, p. 791-806, 2005.

HOLBROOK, J.; RANNIKMAE, M. The meaning of scientific literacy. International Journal of Environmental \& Science Education, Bolu, v. 4, n. 3, p. 275-288, 2009.

LANG, H.; EVANS, D. Models, strategies and methods for effective teaching. New York: Pearson, 2006.

LEITE, L. et al. Questionamento em manuais escolares de ciências: desenvolvimento e validação de uma grelha de análise. Educar em Revista, Curitiba, n. 44, p. 127-143, 2012. Disponível em: <http://dx.doi.org/10.1590/S0104-40602012000200009>. Acesso em: 19 maio 2015.

LOUREIRO, I. A aprendizagem baseada na resolução de problemas e a formulação de questões a partir de contextos problemáticos: um estudo com professores e alunos de física e química. 2008. 166 f. Dissertação (Mestrado em Educação) - Instituto de Educação e Psicologia, Universidade do Minho, Braga, 2008.

MARBACH-AD, G.; SOKOLOVE, P. G. Can undergraduate biology students learn to ask higher level questions? Journal of Research in Science Teaching, Hoboken, v. 37, n. 8, p. 854-870, 2000.

OLIVEIRA, P. A formulação de questões a partir de contextos problemáticos: um estudo com alunos dos ensinos básico e secundário. 2008. 171 f. Dissertação (Mestrado em Educação) - Instituto de Educação e Psicologia, Universidade do Minho, Braga, 2008.

PORTUGAL. Lei de bases do sistema educativo. Lei $n^{\circ}$ 49/2005 de 30 de agosto. [S.1.: s.n.], 2005. Disponível em: <http://www.ipv.pt/secretaria/lei492005.pdf>. Acesso em: 19 maio 2015.

- Ministério da Educação e Ciência. Departamento de Educação Básica. Orientações curriculares $\mathbf{3}^{\mathbf{0}}$ ciclo. Lisboa, 2001.

SANTO, E. M. Os manuais escolares, a construção de saberes e a autonomia do aluno: auscultação a alunos e professores. Revista Lusófona de Educação, Lisboa, v. 8, n. 8, p. 103-115, 2006. Disponível em: <http://revistas.ulusofona.pt/index.php/rleducacao/ article/view/694>. Acesso em: 19 maio 2015.

SCHEIN, Z.; COELHO, S. O papel do questionamento: intervenções do professor e do aluno na construção do conhecimento. Caderno Brasileiro de Ensino de Física, Florianópolis, v. 23, n. 1, p. 68-92, 2006. 
TORRES, J.; PRETO, C.; VASCONCELOS, C. Problem based learning environmental scenarios: an analysis of science students and teachers questioning. Journal of Science Education, Bogotá, v. 14, n. 2, p. 71-74, 2013.

VASCONCELOS, C.; ALMEIDA, A. Aprendizagem baseada na resolução de

problemas no ensino das ciências: propostas de trabalho para ciências naturais, biologia e geologia. Porto: Porto Editora, 2012.

VASCONCELOS, C. et al. Questions in science textbooks: do they prompt students' inquiry and problem based learning? In: BRUGUIÈRE, C.; TIBERGHIEN, A.; CLÉMENT, P. (Ed.). Proceedings of the ESERA 2011 Conference: science learning and citizenship. Lyon: ESERA, 2012. p. 102-107. Disponível em: <http://www.esera.org/media/ebook/ strand6/ebook-esera2011_VASCONCELOS-06.pdf>. Acesso em: 01 set. 2013.

VIEIRA, R. M.; TENREIRO-VIEIRA, C. Estratégias de ensino e de aprendizagem: o questionamento promotor do pensamento crítico. Lisboa: Editora Piaget, 2005. 